\title{
Remission of respiratory symptoms by smoking and occupational exposure in a cohort study
}

\author{
T.M.L. Eagan*, A. Gulsvik*,\#, G.E. Eide ${ }^{\uparrow,+}$, P.S. Bakke*,\#
}

Remission of respiratory symptoms by smoking and occupational exposure in a cohort study. T.M.L. Eagan, A. Gulsvik, G.E. Eide, P.S. Bakke. (C)ERS Journals Ltd 2004. ABSTRACT: Few studies have estimated the remission rates of respiratory symptoms in general populations. No community cohort studies have examined the impact of smoking cessation and previous dust or fumes exposure on the remission of respiratory symptoms.

In the Hordaland County Study, an 11-yr community cohort (1985-1996/1997) from Western Norway, data from 2,819 subjects were used to examine the remission of six respiratory symptoms.

The measured cumulative remission varied from $42.3 \%$ for morning cough to $58.4 \%$ for chronic cough. Smoking cessation was a significant predictor of remission of the cough symptoms and wheezing, with odds ratios (OR) $(95 \%$ confidence intervals $(C I))$ varying from $2.2(1.3-3.7)$ for wheezing to $6.2(3.5-11.2)$ for morning cough, after adjustment for sex, age, pack-years smoked, previous dust or fumes exposure, and educational level. In those not previously exposed to dust or fumes, the adjusted OR $(95 \%$ CI) for the remission of morning cough, phlegm cough, dyspnoea grade 2 , attacks of dyspnoea and wheezing varied from $1.5(0.9-2.5)$ for attacks of dyspnoea to 2.1 (1.1-3.9) for dyspnoea grade 2 , as compared to those previously exposed to dust or fumes.

This study suggests a beneficial effect of smoking cessation and an adverse effect of occupational exposure on the remission of respiratory symptoms. Eur Respir J 2004; 23: 589-594.
*Dept of Thoracic Medicine, Haukeland University Hospital, "Institute of Medicine, University of Bergen, "Centre for Clinical Research, Haukeland University Hospital, and ${ }^{+}$Section for Medical Statistics, University of Bergen, Bergen, Norway.

Correspondence: T. Eagan

Dept of Thoracic Medicine

Haukeland University Hospital

N-5021 Bergen

Norway

Fax: 4755975149

E-mail: Tomas.Eagan@med.uib.no

Keywords: Cohort study

occupational exposure

remission

respiratory symptoms

smoking

Received: April 112003

Accepted after revision: November 112003
A frequent observation from clinical practice is the transient nature of respiratory symptoms, both in patients with known obstructive lung disease and in otherwise healthy subjects. Knowledge of the natural history of respiratory symptoms is important when evaluating patients with or without known disease. While several community studies have assessed the incidence of respiratory symptoms [1-7], only two prior studies have examined the remission of respiratory symptoms in general population cohorts $[4,6]$.

Several community studies have shown a beneficial effect of smoking cessation on the decline in forced expiratory volume in one second (FEV1) [8-13]. However, only one previous cohort study has examined the effect of smoking cessation on respiratory symptoms, although this study compared incidence rates to persistence rates of the symptoms, not remission rates [14].

No community-based data have been found concerning how the remission of respiratory symptoms varies by occupational dust or fumes exposure or educational level. The current authors have previously shown that occupational exposure is an important risk factor for respiratory symptoms in a Norwegian community [15].

In the present study, data were used from the Hordaland County Study, a general population cohort followed for $11 \mathrm{yrs}$, to estimate the cumulative remission of six respiratory symptoms. Predictors examined were sex, age, smoking habits, previous dust or fumes exposure, and educational level.

\begin{abstract}
Methods
Study population

In $1985,4,995$ randomly sampled subjects, aged $15-70$ yrs, were surveyed in the county of Hordaland in Western Norway, with a mailed questionnaire regarding respiratory disease. The response rate was $90 \%$. The sampling procedure and comparisons of responders versus nonresponders have been previously described [16]. A follow-up survey was conducted between the autumn of 1996 and spring of 1997 among the sub-sample of 3,786 subjects living in the city of Bergen and the 11 surrounding municipalities. After the exclusion of subjects not responding at baseline $(n=416)$, or those who died within the follow-up period $(\mathrm{n}=189), 3,181$ subjects were eligible for follow-up. A total of 2,819 subjects (89\%) replied to a mailed questionnaire. The sampling procedure in 1996/ 1997 has been previously described in detail [17].
\end{abstract}

\section{The questionnaires}

The wording of the questions on respiratory symptoms is available in Appendix 1. The questions have previously been validated against lung function and bronchial reactivity [18], and compared with the British Medical Research Council questionnaire on chronic bronchitis [19]. The definitions of 
smoking habits and pack-years have been published previously [7]. In 1985, the subjects were asked whether they had ever worked in a place with much dust or fumes in the air, and this was used as an indicator of previous airborne occupational exposure. In 1996/1997, the subjects were asked about their highest obtained education. By then, the youngest subjects were $\geqslant 26$ yrs old and were likely to have reached university level education, if that was their "highest obtained education". Educational level was categorised into three categories: 1) those with up to 9 yrs of schooling (primary), those with 12 yrs of schooling (secondary) and those with a higher degree of education (university). Educational level is a commonly used indicator of socio-economic status [20, 21].

\section{Data analysis}

The cumulative remission of any symptom was defined as the proportion of subjects having a symptom at baseline who no longer reported the symptom at follow-up. Logistic regression models were used to estimate the adjusted odds ratios (ORs). The explanatory variables were sex, age, changes in smoking habits, pack-years until follow-up, dust or fumes exposure prior to baseline, and educational level (as reported at follow-up). The outcome variable was the symptom in question and a significance level of $\mathrm{p}<0.05$ was chosen. Increasing age correlated with decreasing remission of all symptoms, when age was modelled as a categorical variable with 10-yr-category intervals. Pack-years smoked exhibited a similar relationship. Age and pack-years were thus modelled as continuous variables. Smoking habits were modelled as a five-category variable based on whether the subjects were smoking at baseline and/or follow-up, as follows: never-to-never, non-to-current (consisting both of never-tocurrent and ex-to-current), current-to-current, current-to-ex, and ex-to-ex. The possible first-order interactions were examined between smoking habits and the co-variables sex, age, educational level, previous dust or fumes exposure and pack-years smoked, respectively. Likewise, all first-order interactions between previous dust or fumes exposure and the other co-variables were examined. Finally, the regression analyses were conducted for each sex separately.

\section{Results}

The characteristics of the Hordaland County Study cohort are presented in table 1 . There were more female neversmokers than male never-smokers. In addition, male ex- and current-smokers had smoked more pack-years than female smokers. Three times more males than females reported previous occupational dust or fumes exposure in 1985 (table 1). Thus, for the two main exposures, the male subjects were more heavily exposed. The males were also slightly younger than the females, and there were more males with a higher education (table 1 ).

The baseline prevalences of the six respiratory symptoms are shown in table 2 . In general, the symptom prevalence at baseline was higher in subjects with a greater smoking consumption, previous dust or fumes exposure, and lower educational level (table 2).

The 11-yr cumulative remissions of the six symptoms are shown in table 3 . The remission was highest for chronic cough and attacks of dyspnoea, and lowest for morning cough. There were no significant differences between the sexes in the remission of any symptom. For dyspnoea grade 2 and the cough symptoms, the remission decreased with increasing age. Current-to-ex smokers had a higher remission than current-to-current smokers of all symptoms, except dyspnoea
Table 1.-Characteristics of the Hordaland County Study cohort

\begin{tabular}{lccc}
\hline & Total & Females & Males \\
\hline Subjects n & 2819 & 1467 & 1352 \\
Age in 1985 & $38.2 \pm 15.2$ & $38.9 \pm 15.7$ & $37.4 \pm 14.6$ \\
Smoking habits & & & \\
$\quad$ Current-to-current & $776(28.9)$ & $381(27.6)$ & $395(30.4)$ \\
$\quad$ Non-to-current & $135(5.0)$ & $68(4.9)$ & $67(5.2)$ \\
Current-to-ex & $293(10.9)$ & $136(9.8)$ & $157(12.1)$ \\
Ex-to-ex & $420(15.7)$ & $167(12.1)$ & $253(19.5)$ \\
$\quad$ Never-to-never & $1058(39.5)$ & $631(45.6)$ & $427(32.9)$ \\
Pack-years until 1996/97 & $12.0(6-21)$ & $9.9(5-18)$ & $15.0(8-24)$ \\
Dust or fumes exposure & & & \\
$\quad$ in 1985 & & & \\
$\quad$ Yes & $798(28.3)$ & $191(13.0)$ & $607(44.9)$ \\
$\quad$ No & $2021(71.7)$ & $1276(87.0)$ & $745(55.1)$ \\
Educational level & & & \\
$\quad$ in 1996/97 & & & \\
$\quad$ Primary & $501(17.8)$ & $279(19.0)$ & $222(16.4)$ \\
$\quad$ Secondary & $1536(54.5)$ & $813(55.4)$ & $723(53.5)$ \\
$\quad$ University & $720(25.5)$ & $341(23.2)$ & $379(28.0)$ \\
\hline
\end{tabular}

Data are presented as $\mathrm{n}(\%)$, median (interquartile range) or as mean \pm SD. ${ }^{\#}$ : consists of never-to-current and ex-to-current smokers; ${ }^{\circ}$ : only among current or ex-smokers.

grade 2. The remission of all symptoms decreased with heavier smoking measured in pack-years, although this was only statistically significant for phlegm cough, chronic cough and dyspnoea grade 2. Subjects with previous dust or fumes exposure had lower remission rates for all symptoms, whereas subjects with a higher degree of education had higher remission rates of all symptoms (table 3 ).

The adjusted ORs for the remission of the six symptoms are presented in table 4. After adjustment of the variables included in the table, males had approximately twice the chance for remission of dyspnoea grade 2 when compared to females. Higher age was significantly associated with a decrease in remission for the cough symptoms and dyspnoea grade 2 . The odds of remission of morning cough were approximately six times higher in those who had given up smoking as compared to persistent smokers, after adjustment for sex, age, pack-years, previous dust or fumes exposure, and educational level. The odds of remission among current-to-ex smokers were significantly higher than current-to-current smokers for all cough symptoms and wheezing. For all symptoms except wheezing, a higher smoking consumption was associated with a lower remission, however, this was not statistically significant.

The association between previous dust or fumes exposure and a decrease in remission was strengthened after adjustment, whereas educational level failed to be significantly associated with remission, except for the remission of chronic cough among those with a university level education.

There was a significant interaction between age and changes in smoking habits for the remission of dyspnoea grade 2 . Increasing age predicted a lower chance for remission of dyspnoea grade 2 in all smoking categories, except currentto-current smokers. The OR (with 95\% confidence interval (CI)) for the effect of a 10-yr increase in age, in current-tocurrent smokers, on the remission of dyspnoea grade 2 was $1.1(0.7-1.6)$. For the other smoking categories, the ORs for the effect of age on the remission of dyspnoea grade 2 varied between $0.3(0.1-1.2)$ among non-to-current smokers to 0.6 (0.4-0.8) among never-to-never smokers. There were no overt differences in the adjusted ORs for remission of any of the symptoms when the analyses were conducted for each sex separately. 
Table 2. - The prevalence of respiratory symptoms (\%) at baseline in 1985 for the Hordaland County Study

\begin{tabular}{|c|c|c|c|c|c|c|c|}
\hline & $\begin{array}{c}\text { Subjects } \\
\mathrm{n}\end{array}$ & $\begin{array}{l}\text { Morning } \\
\text { cough }\end{array}$ & $\begin{array}{l}\text { Phlegm } \\
\text { cough }\end{array}$ & $\begin{array}{l}\text { Chronic } \\
\text { cough }\end{array}$ & $\begin{array}{l}\text { Dyspnoea } \\
\text { grade } 2\end{array}$ & $\begin{array}{l}\text { Attacks of } \\
\text { dyspnoea }\end{array}$ & Wheezing \\
\hline \multicolumn{8}{|l|}{ Sex } \\
\hline Females & 1467 & 18.2 & 17.2 & 8.0 & 11.8 & 13.0 & 18.5 \\
\hline Males & 1352 & 23.7 & 25.0 & 11.2 & 8.1 & 11.3 & 22.0 \\
\hline \multicolumn{8}{|l|}{ Age in 1985} \\
\hline $15-29$ & 980 & 19.2 & 21.7 & 9.9 & 6.0 & 10.9 & 22.2 \\
\hline $30-49$ & 1114 & 20.4 & 20.8 & 9.1 & 9.3 & 12.1 & 18.0 \\
\hline $50-70$ & 725 & 23.7 & 20.1 & 10.5 & 16.4 & 13.9 & 20.7 \\
\hline \multicolumn{8}{|l|}{ Smoking habits } \\
\hline Current-to-current & 776 & 37.2 & 32.9 & 17.3 & 11.0 & 17.4 & 36.5 \\
\hline Non-to-current & 135 & 16.3 & 17.8 & 7.4 & 8.9 & 15.6 & 18.5 \\
\hline Current-to-ex & 293 & 30.7 & 28.7 & 14.3 & 17.1 & 13.0 & 31.1 \\
\hline Ex-to-ex & 420 & 9.3 & 13.8 & 13.8 & 9.1 & 11.2 & 11.9 \\
\hline Never-to-never & 1058 & 11.8 & 14.2 & 6.1 & 8.2 & 8.4 & 9.5 \\
\hline \multicolumn{8}{|l|}{ Pack-yrs smoked } \\
\hline $1-10$ & 656 & 14.9 & 19.4 & 6.6 & 5.8 & 10.8 & 18.0 \\
\hline $11-19$ & 496 & 29.0 & 25.0 & 12.5 & 11.9 & 14.1 & 31.7 \\
\hline$\geqslant 20$ & 431 & 43.4 & 36.2 & 20.9 & 18.3 & 20.4 & 38.5 \\
\hline \multicolumn{8}{|c|}{ Dust or fumes exposure in 1985} \\
\hline Yes & 798 & 27.9 & 30.2 & 14.2 & 12.7 & 15.3 & 28.6 \\
\hline No & 2021 & 18.0 & 17.3 & 8.0 & 9.0 & 10.9 & 16.9 \\
\hline \multicolumn{8}{|c|}{ Educational level in $1996 / 97$} \\
\hline Primary & 501 & 25.6 & 23.0 & 11.6 & 15.6 & 12.6 & 23.8 \\
\hline Secondary & 1536 & 22.2 & 21.4 & 10.0 & 9.6 & 13.5 & 21.2 \\
\hline University & 720 & 15.1 & 18.5 & 7.8 & 6.7 & 8.8 & 15.1 \\
\hline Total & 2819 & 21.1 & 20.7 & 10.0 & 11.2 & 12.2 & 20.6 \\
\hline
\end{tabular}

Table 3. - The 11-yrs cumulative remission (\%) ${ }^{\#}$ of six respiratory symptoms in the Hordaland County Study

\begin{tabular}{|c|c|c|c|c|c|c|}
\hline & $\begin{array}{l}\text { Morning } \\
\text { cough }\end{array}$ & $\begin{array}{l}\text { Phlegm } \\
\text { cough }\end{array}$ & $\begin{array}{c}\text { Chronic } \\
\text { cough }\end{array}$ & $\begin{array}{l}\text { Dyspnoea } \\
\text { grade } 2\end{array}$ & $\begin{array}{l}\text { Attacks of } \\
\text { dyspnoea }\end{array}$ & Wheezing \\
\hline \multicolumn{7}{|l|}{ Sex } \\
\hline Females & 40.5 & 51.4 & 57.6 & 41.0 & 54.7 & 44.9 \\
\hline Males & 43.8 & 48.8 & 59.0 & 50.5 & 58.8 & 47.5 \\
\hline \multicolumn{7}{|l|}{ Age in 1985} \\
\hline $15-29$ & $49.5^{*}$ & $59.2^{*}$ & $69.1^{*}$ & $69.5^{*}$ & 57.9 & 46.8 \\
\hline $30-49$ & 42.3 & 46.6 & 55.5 & 47.1 & 59.3 & 44.3 \\
\hline $50-70$ & 34.3 & 41.2 & 48.7 & 30.3 & 51.5 & 48.0 \\
\hline \multicolumn{7}{|l|}{ Smoking habits } \\
\hline Current-to-current & $33.9 *$ & $39.6^{*}$ & 53.7 & 50.6 & 54.1 & $40.3^{*}$ \\
\hline Non-to-current & 36.4 & 50.0 & 50.0 & 66.7 & 66.7 & 36.0 \\
\hline Current-to-ex & 72.2 & 56.0 & 73.8 & 38.0 & 65.8 & 57.1 \\
\hline Ex-to-ex & 35.9 & 56.9 & 46.2 & 44.7 & 53.2 & 54.0 \\
\hline Never-to-never & 41.6 & 61.3 & 65.6 & 41.4 & 56.2 & 45.0 \\
\hline \multicolumn{7}{|l|}{ Pack-yrs smoked } \\
\hline $1-10$ & 53.1 & $61.3^{*}$ & $74.4^{*}$ & $71.1^{*}$ & 60.6 & 45.0 \\
\hline $11-19$ & 42.4 & 57.5 & 54.8 & 45.8 & 54.3 & 48.3 \\
\hline$\geqslant 20$ & 36.4 & 48.4 & 50.0 & 38.0 & 56.8 & 42.7 \\
\hline \multicolumn{7}{|c|}{ Dust or fumes exposure in 1985} \\
\hline Yes & $35.9^{*}$ & $43.2^{*}$ & 55.8 & 39.6 & 50.8 & $41.2^{*}$ \\
\hline No & 46.2 & 54.6 & 60.3 & 47.5 & 59.7 & 49.6 \\
\hline \multicolumn{7}{|c|}{ Educational level in $1996 / 97$} \\
\hline Primary & $37.5^{*}$ & 47.8 & $43.1^{*}$ & $39.7^{*}$ & $47.6^{*}$ & 44.5 \\
\hline Secondary & 40.5 & 48.0 & 57.5 & 41.2 & 55.3 & 44.0 \\
\hline University & 54.1 & 58.7 & 75.0 & 62.5 & 69.8 & 50.5 \\
\hline Total & 42.3 & 49.9 & 58.4 & 44.7 & 56.6 & 46.2 \\
\hline
\end{tabular}

\section{Discussion}

The 11-yr cumulative remission varied from 42 to $58 \%$ for the six respiratory symptoms. There was a beneficial effect of smoking cessation on the remission of cough, attacks of dyspnoea and wheezing. This is the first study to show that previous dust or fumes exposure has a negative impact on the remission of respiratory symptoms in a general population sample.

First, there are some methodological considerations. A 
Table 4. - The adjusted odds ratios for the remission of six respiratory symptoms in the Hordaland County Study

\begin{tabular}{|c|c|c|c|c|c|c|}
\hline & $\begin{array}{l}\text { Morning } \\
\text { cough }\end{array}$ & $\begin{array}{l}\text { Phlegm } \\
\text { cough }\end{array}$ & $\begin{array}{l}\text { Chronic } \\
\text { cough }\end{array}$ & $\begin{array}{l}\text { Dyspnoea } \\
\text { grade } 2\end{array}$ & $\begin{array}{l}\text { Attacks of } \\
\text { dyspnoea }\end{array}$ & Wheezing \\
\hline Subjects $n$ & 547 & 551 & 253 & 260 & 317 & 529 \\
\hline \multicolumn{7}{|l|}{ Sex } \\
\hline Females & 1 & 1 & 1 & 1 & 1 & 1 \\
\hline Males & $1.2(0.8-1.9)$ & $1.0(0.7-1.5)$ & $1.2(0.7-2.2)$ & $2.0(1.01-3.8)$ & $1.4(0.8-2.5)$ & $1.1(0.8-1.7)$ \\
\hline Age per 10 -yr increase & $0.8(0.7-0.97)$ & $0.8(0.7-0.9)$ & $0.8(0.6-0.99)$ & $0.6(0.5-0.8)$ & $1.0(0.8-1.2)$ & $0.9(0.8-1.02)$ \\
\hline \multicolumn{7}{|l|}{ Smoking habits } \\
\hline Current-to-current & 1 & 1 & 1 & 1 & 1 & 1 \\
\hline Non-to-current & $0.8(0.3-2.1)$ & $1.3(0.5-3.1)$ & $0.6(0.2-2.4)$ & $2.1(0.5-8.5)$ & $1.2(0.4-3.5)$ & $0.8(0.4-2.0)$ \\
\hline Current-to-ex & $6.2(3.5-11.2)$ & $2.6(1.5-4.5)$ & $3.4(1.4-8.4)$ & $0.9(0.4-2.1)$ & $1.4(0.6-3.1)$ & $2.2(1.3-3.7)$ \\
\hline Ex-to-ex & $1.0(0.5-2.4)$ & $2.5(1.3-5.0)$ & $0.5(1.0-2.0)$ & $1.5(0.5-4.0$ & $0.7(0.3-1.6)$ & $2.1(1.03-4.2)$ \\
\hline Never-to-never & $1.0(0.5-2.0)$ & $2.3(1.3-4.3)$ & $1.0(0.4-2.6)$ & $0.9(0.3-2.6)$ & $0.8(0.4-1.8)$ & $1.5(0.8-2.8)$ \\
\hline Pack-years per 10 yrs increase & $0.9(0.7-1.1)$ & $0.9(0.8-1.1)$ & $0.8(0.6-1.01)$ & $0.8(0.6-1.1)$ & $0.9(0.7-2.4)$ & $1.1(0.9-1.3)$ \\
\hline \multicolumn{7}{|l|}{ Dust or fumes exposure in 1985} \\
\hline Yes & 1 & 1 & 1 & 1 & 1 & 1 \\
\hline No & $1.7(1.1-2.5)$ & $1.5(1.02-2.2)$ & $1.1(0.6-2.0)$ & $2.1(1.1-3.9)$ & $1.5(0.9-2.5)$ & $1.6(1.1-2.3)$ \\
\hline \multicolumn{7}{|l|}{ Educational level in $1996 / 97$} \\
\hline Primary & 1 & 1 & 1 & 1 & 1 & 1 \\
\hline Secondary & $1.0(0.6-1.6)$ & $0.8(0.5-1.3)$ & $1.6(0.8-3.1)$ & $0.7(0.4-1.3)$ & $1.3(0.7-2.4)$ & $0.8(0.5-1.3)$ \\
\hline University & $1.5(0.8-2.8)$ & $0.9(0.5-1.5)$ & $3.0(1.3-7.2)$ & $0.9(0.4-2.3)$ & $2.2(0.97-5.1)$ & $1.1(0.6-1.9)$ \\
\hline
\end{tabular}

Data are presented as odds ratio $(95 \%$ confidence interval).

reporting error occurs when a subject replies "yes" when he or she should have replied "no" (over-reporting), or vice versa (under-reporting). In a longitudinal study, a possible reporting error in the outcome of interest can affect the estimates of the crude incidence or remission rates [22]. To what degree the crude incidence or remission is affected is dependent on the degree of reporting error and the prevalence of the outcome at baseline. The estimates of the remission are particularly vulnerable to a misclassification of the outcome, due to the inclusion of only symptomatic subjects at baseline. In the event of even a small over-reporting of symptoms, a relatively large over-estimation of the crude remission rate is possible (see Appendix 2). Furthermore, it has been shown that a nondifferential measurement error in the outcome leads to an underestimation of the OR and a widening of the CI in an ordinary logistic regression analysis [23]. When the extent of misclassification is known, a method exists for correcting the estimates [23]. However, a recently published paper has shown that this conservative effect on the OR may not always be true for longitudinal studies [24], in which case there is currently no established method for correction of the estimates.

It is not known whether or not there is an actual reporting error in the present study. Ideally, validation of the outcome against an objective measure would provide an estimate of a possible misclassification. However, it is intrinsically difficult to produce an objective validation of morning cough, for example, in a large general population sample. Another approach would be to assess the repeatability of the answers to the questionnaire. This is also difficult in a study of respiratory symptoms, as one needs to ask the question while the symptom is still likely to be present, while not so close in time that the subject remembers their former reply. At least one study has been conducted on the repeatability on a questionnaire on respiratory symptoms in a general population from Western Norway [18]. Although repeatability was high, and in accordance with repeatability found in a study using the IUATLD Bronchial Symptom Questionnaire [25], there was almost certainly some misclassification in the outcome. Although the present authors believe under-reporting is more likely than over-reporting in a general population, cumulative remission rates are likely to be overestimated and there is some uncertainty regarding the precision of the estimated ORs.
Secondly, the 189 subjects who died before the follow-up study had a higher prevalence of all symptoms, except attacks of dyspnoea, at the baseline survey in 1985, as compared to those who survived. These 189 subjects were less likely to have a remission of their symptoms and this could also have lead to an overestimation of the remission.

Thirdly, the exact wording of the question regarding wheezing was changed from baseline to follow-up. Whereas the initial question asked about wheezing-ever, the follow-up is limited to wheezing within the last 12 months. This might lead to over-estimating the cumulative remission of wheezing.

Finally, the present study does not have data on the history of occupational exposure within follow-up for the sample. This is unfortunate, as it would be of interest to know whether reducing occupational exposure within the follow-up would increase the remission.

Two previous cohort studies have examined cumulative remission rates of several respiratory symptoms $[4,6]$. In the Tucson, Arizona and Krakow, Poland cohorts, the follow-up lasted 12.2 and $13 \mathrm{yrs,}$ respectively [4]. In general, the estimated annual remission rates from the current study are comparable to both the Tucson and the Krakow cohorts for chronic cough, phlegm cough, dyspnoea, attacks of dyspnoea and wheezing. In the Tucson/Krakow cohorts, the ORs for remission decreased with higher age for chronic cough and for dyspnoea, but not for wheezing and attacks of dyspnoea, and for phlegm cough only in smokers [4]. The present study confirms the effect of higher age on decreasing remission of the cough symptoms and dyspnoea, and not on attacks of dyspnoea and possibly wheezing. However, in the present study, the effect of age on the remission of phlegm cough was not dependent on smoking habits. The study of the Tucson/ Krakow cohorts examined only the effect of current-tocurrent smokers versus never-to-never smokers on the remission, finding a lesser chance for remission of dyspnoea among male persistent smokers and of chronic cough among persistent smokers in both sexes [4].

The estimated annual remission rates in the cohort study from the Netherlands were two to three times higher for all symptoms as compared with both the Tucson/Krakow cohorts and the present study [6]. However, the follow-up in the Dutch study lasted 3 yrs and a comparison of estimated 
annual remission between studies with varying lengths of follow-up may not be valid.

The cough symptoms can be interpreted as markers of inflammatory processes, reacting to irritant stimuli. The beneficial effect of smoking cessation on the remission of the cough symptoms is presumably due to the removal of the irritant(s). Dyspnoea on exertion can be caused by disease in the small airways and impairment of gas exchange [26]. The fact that smoking cessation did not have a beneficial effect on the remission of dyspnoea grade 2 could indicate irreversible damage. This is in accordance with studies on lung function in smokers, where ex-smokers did not regain their lost FEV1 after smoking cessation $[8,9,11,12]$.

Attacks of dyspnoea and wheezing are indicators of intermittent airways obstruction. The finding of a beneficial effect of smoking cessation on the remission of wheezing and possibly attacks of dyspnoea could implicate a beneficial effect also on the remission of asthma.

Several cross-sectional community-based studies have observed a higher prevalence of respiratory symptoms in subjects with occupational airborne exposure as compared to those without occupational exposure [27-32]. Theoretically, this may be due to increased incidence or reduced remission of respiratory symptoms in exposed versus unexposed subjects. The present authors have previously shown the former to be the case [15]. This is the first study to show that there is an actual negative effect of previous dust or fumes exposure on the remission of respiratory symptoms.

Educational level did not significantly affect the remission of the symptoms, with the possible exceptions of a beneficial effect of a university level education on the remission of chronic cough and attacks of dyspnoea. The authors are not aware of previous studies on remission of respiratory symptoms adjusting for educational level or other measures of socio-economic status.

In conclusion, this study confirms the beneficial effect of smoking cessation to the remission of several respiratory symptoms. In addition, this is the first study to show a decreased remission of respiratory symptoms among subjects with prior occupational exposure, after adjustment for sex, age, smoking habits and educational level.

\section{Appendix 1}

The wording of the questions in 1985 and 1996/1997 regarding respiratory symptoms were similar, except for the questions on wheezing.

\section{5}

Do you usually cough or clear your throat in the morning? [yes, no]

Do you usually have phlegm when coughing? [yes, no]

Do you have a cough for $\geqslant 3$ months altogether during a year? [yes, no]

Are you breathless when you climb two flights of stairs at an ordinary pace? [yes, no] (dyspnoea grade 2)

Do you sometimes experience attacks of breathlessness? [yes, no]

Do you ever have wheezing in your chest? [yes, no]

\section{$1996 / 1997$}

Have you had wheezing in your chest in the last 12 months? [yes, no]

\section{Appendix 2}

Consider a cohort study with a sample size of 1,000 and two time points. The baseline prevalence of the symptom in question is $15 \%$, the true cumulative incidence $20 \%$ and the true cumulative remission $10 \%$ (table 5).

Table 5. - True findings from a hypothetical study

\begin{tabular}{lccc}
\hline & \multicolumn{3}{c}{ Follow-up } \\
\cline { 2 - 4 } & No & Yes & Sum \\
\hline Baseline & & & \\
No & 680 & 170 & 850 \\
Yes & 15 & 135 & 150 \\
Sum & 695 & 305 & 1000 \\
\hline
\end{tabular}

Given that 3\% of subjects will over-report (i.e. say they have a symptom when in fact they do not) and 5\% of the subjects will under-report (say they do not have a symptom when in fact they do), at both baseline and follow-up, table 6 would be obtained.

Table 6.-Observed findings in the study in the presence of a reporting error

\begin{tabular}{lccc}
\hline & \multicolumn{3}{c}{ Follow-up } \\
\cline { 2 - 4 } & No & Yes & Sum \\
\hline Baseline & & & \\
No & 649.1 & 182.88 & 832 \\
Yes & 40.28 & 127.72 & 168 \\
Sum & 689.4 & 310.6 & 1000 \\
\hline
\end{tabular}

In which case a cumulative incidence would be estimated as follows:

$$
(182.88 / 832) \times 100=22 \%
$$

and the cumulative remission would be estimated as follows:

$$
(40.28 / 168) \times 100=24 \%
$$

\section{References}

1. Ferris BG, Higgins IT, Higgins MW, Peters JM. Chronic nonspecific respiratory disease in Berlin, New Hampshire, 1961 to 1967. A follow-up study. Am Rev Respir Dis 1973; 107: $110-122$.

2. Huhti E, Ikkala J. A 10-year follow-up study of respiratory symptoms and ventilatory function in a middle-aged rural population. Eur J Respir Dis 1980; 61: 33-45.

3. Beck GJ, Doyle CA, Schachter EN. A longitudinal study of respiratory health in a rural community. Am Rev Respir Dis 1982; 125: 375-381.

4. Krzyzanowski M, Lebowitz MD. Changes in chronic respiratory symptoms in two populations of adults studied longitudinally over 13 years. Eur Respir J 1992; 5: 12-20.

5. Ronmark E, Lundback B, Jonsson E, Jonsson AC, Lindstrom M, Sandstrom T. Incidence of asthma in adults - report from the Obstructive Lung Disease in Northern Sweden Study. Allergy 1997; 52: 1071-1078.

6. $\mathrm{Xu} \mathrm{X,} \mathrm{Rijcken} \mathrm{B,} \mathrm{Schouten} \mathrm{JP,} \mathrm{Weiss} \mathrm{ST.} \mathrm{Airways}$ responsiveness and development and remission of chronic respiratory symptoms in adults. Lancet 1997; 350: 14311434. 
7. Eagan TM, Bakke PS, Eide GE, Gulsvik A. Incidence of asthma and respiratory symptoms by sex, age and smoking in a community study. Eur Respir $J$ 2002; 19: 599-605.

8. $\mathrm{Xu} \mathrm{X}$, Weiss ST, Rijcken B, Schouten JP. Smoking, changes in smoking habits, and rate of decline in FEV1: new insight into gender differences. Eur Respir $J$ 1994; 7 : 1056-1061.

9. Tashkin DP, Clark VA, Coulson AH, et al. The UCLA population studies of chronic obstructive respiratory disease. VIII. Effects of smoking cessation on lung function: a prospective study of a free-living population. Am Rev Respir Dis 1984; 130: 707-715.

10. Sherrill DL, Holberg CJ, Enright PL, Lebowitz MD, Burrows B. Longitudinal analysis of the effects of smoking onset and cessation on pulmonary function. Am J Respir Crit Care Med 1994; 149: 591-597.

11. Camilli AE, Burrows B, Knudson RJ, Lyle SK, Lebowitz MD. Longitudinal changes in forced expiratory volume in one second in adults. Effects of smoking and smoking cessation. Am Rev Respir Dis 1987; 135: 794-799.

12. Lange P, Groth S, Nyboe GJ, Mortensen J, Appleyard M, Jensen G, Schnohr P. Effects of smoking and changes in smoking habits on the decline of FEV1. Eur Respir J 1989; 2: 811-816.

13. Pelkonen M, Notkola IL, Tukiainen H, Tervahauta M, Tuomilehto J, Nissinen A. Smoking cessation, decline in pulmonary function and total mortality: a 30 year follow up study among the Finnish cohorts of the Seven Countries Study. Thorax 2001; 56: 703-707.

14. Krzyzanowski M, Robbins DR, Lebowitz MD. Smoking cessation and changes in respiratory symptoms in two populations followed for 13 years. Int J Epidemiol 1993; 22: 666-673.

15. Eagan TM, Gulsvik A, Eide GE, Bakke PS. Occupational airborne exposure and the incidence of respiratory symptoms and asthma. Am J Respir Crit Care Med 2002; 166: 933-938.

16. Bakke P, Gulsvik A, Lilleng P, Overa O, Hanoa R, Eide GE. Postal survey on airborne occupational exposure and respiratory disorders in Norway: causes and consequences of non-response. J Epidemiol Community Health 1990; 44: 316-320.

17. Eagan T, Eide G, Gulsvik A, Bakke P. Nonresponse in a community cohort study. Predictors and consequences for exposure-disease associations. J Clin Epidemiol 2002; 55: 775.

18. Gulsvik A, Bakke P, Humerfelt S, Omenaas E, Baste V. Measurements of respiratory symptoms and sample size to detect a given difference between treatment groups in obstructive lung disease. Eur Respir Rev 1991; 1: 436-443.
19. Brogger JC, Bakke PS, Gulsvik A. Comparison of respiratory symptoms questionnaires. Int J Tuberc Lung Dis 2000; 4: 83-90.

20. Liberatos P, Link BG, Kelsey JL. The measurement of social class in epidemiology. Epidemiol Rev 1988; 10: 87-121.

21. Bakke PS, Hanoa R, Gulsvik A. Educational level and obstructive lung disease given smoking habits and occupational airborne exposure: a Norwegian community study. Am J Epidemiol 1995; 141: 1080-1088.

22. Chinn S. Follow-up studies of symptoms of asthma: the problem of reporting error (abstract). Eur Respir J 2003; 22: Suppl. 45, 295s.

23. Magder LS, Hughes JP. Logistic regression when the outcome is measured with uncertainty. Am J Epidemiol 1997; 146: 195-203.

24. Wolfe R, Carlin JB, Patton GC. Transitions in an imperfectly observed binary variable: depressive symptomatology in adolescents. Stat Med 2003; 22: 427-440.

25. Burney PG, Laitinen LA, Perdrizet S, et al. Validity and repeatability of the IUATLD (1984) Bronchial Symptoms Questionnaire: an international comparison. Eur Respir $J$ 1989; 2: 940-945.

26. Welle I, Eide GE, Bakke PS, Gulsvik A. The single-breath transfer factor for carbon monoxide and respiratory symptoms in a Norwegian community sample. Eur Respir $J$ 1999; 14: 1320-1325.

27. Korn RJ, Dockery DW, Speizer FE, Ware JH, Ferris BG Occupational exposures and chronic respiratory symptoms. A population-based study. Am Rev Respir Dis 1987; 136: 298-304.

28. Krzyzanowski M, Kauffmann F. The relation of respiratory symptoms and ventilatory function to moderate occupational exposure in a general population. Results from the French PAARC study of 16,000 adults. Int J Epidemiol 1988; 17: 397-406.

29. Bakke P, Eide GE, Hanoa R, Gulsvik A. Occupational dust or gas exposure and prevalences of respiratory symptoms and asthma in a general population. Eur Respir $J$ 1991; 4: 273-278.

30. Viegi G, Prediletto R, Paoletti P, et al. Respiratory effects of occupational exposure in a general population sample in north Italy. Am Rev Respir Dis 1991; 143: 510-515.

31. Xu X, Christiani DC, Dockery DW, Wang L. Exposureresponse relationships between occupational exposures and chronic respiratory illness: a community-based study. $\mathrm{Am}$ Rev Respir Dis 1992; 146: 413-418.

32. Zock JP, Sunyer J, Kogevinas M, Kromhout H, Burney P, Anto JM. Occupation, chronic bronchitis, and lung function in young adults. An international study. Am J Respir Crit Care Med 2001; 163: 1572-1577. 